\title{
Serum Adiponectin, Body Adiposity and Metabolic Profile in Relation to Obesity among Egyptian Children with Down Syndrome
}

\section{Sohier Yahia}

Mansoura University Faculty of Medicine

\section{Reham El-Farahaty}

Mansoura University Faculty of Medicine

Abdel-Hady EL-Gilany

Mansoura University Faculty of Medicine

\section{Rasha Shoaib}

Damietta University Faculty of Science

\section{Rowayda Ramadan}

Mansoura University Children's Hospital

Nanees Salem ( $\square$ nanees.salem@gmail.com )

Mansoura University Faculty of Medicine https://orcid.org/0000-0001-6783-9095

\section{Research Article}

Keywords: Down syndrome, Obesity, Metabolic syndrome, Adiponectin, Body adiposity, Insulin resistance.

Posted Date: March 17th, 2021

DOl: https://doi.org/10.21203/rs.3.rs-306851/v1

License: (9) (i) This work is licensed under a Creative Commons Attribution 4.0 International License. Read Full License 


\section{Abstract}

Children with Down syndrome (DS) have a higher risk for obesity. Adiponectin plays a crucial role in obesity-related cardiometabolic comorbidities. We aimed to determine whether body adiposity indicators, metabolic syndrome (MetS) components, serum adiponectin and insulin resistance indicies are different in "obese-DS" children compared to BMI-Z-score-matched "obese-control" and to clarify the usefulness of serum adiponectin as a biomarker for MetS in DS children. Cross-sectional study included 150 prepubertal children classfied into three groups; obese-DS $(n=50)$, obese-control $(n=50)$ and normalweight-control $(n=50)$. Participants were evaluated for waist-circumference $(W C)$, body adiposity, serum triglycerides, HDL-C, adiponectin and Homeostasis-Model-Assessment of Insulin-Resistance (HOMA-IR). MetS was defined using modified Adult Treatment Panel III-criteria. Obese-DS had significantly higher WC, \%body fat, total-fat mass, trunk-fat mass, trunk/appendicular-FM ratio, triglycerides, insulin and HOMA-IR and significantly lower HDL-C values compared to obese-control. Higher prevalence of MetS and its components were observed in obese-DS that was evident at younger age. Serum adiponectin was significantly lower in obese-DS compared with obese-control and in obese-DS children with MetS compared to obese-control with MetS. The decrease in adiponectin with increasing grades of obesity was pronounced in obese-DS. Adiponectin exhibited strong correlations with body adiposity, several MetS components and HOMA-IR in obese-DS. Adiponectin performed better as a biomarker for MetS among obese-DS (AUC $=0.808)$ than among obese-control (AUC $=0.674)$. In conclusion, prepubertal obese-DS displayed excess body adiposity with pronounced central fat distribution, atherogenic lipid profile and higher insulin resistance compared to matched obese-control. Adiponectin performed better as potential biomarker of MetS in obese-DS than among obese-control.

\section{Authors Summary}

\section{What is known?}

- Children with Down syndrome (DS) have a higher risk for obesity.

\section{What is new?}

- Obese-DS children displayed excess body adiposity, pronounced central fat distribution, atherogenic lipid profile, higher insulin resistance indices, higher rate of MetS compared to matched obesecontrol.

- Lower serum adiponectin was observed in obese-DS compared to obese-control and in obese-DS with MetS compared to obese-control with MetS.

- The decrease in adiponectin level with increasing the severity of obesity was more pronounced in obese-DS than among obese-control.

- Adiponectin performed better as a potential biomarker for MetS among obese-DS than among obesecontrol. 


\section{Introduction}

Down syndrome (DS) (OMIM \#190685) is the most common human autosomal aneuploidy, with an incidence of approximately $1 / 1000$ live births worldwide, resulting from the presence of a supernumerary copy of the human chromosome 21 (HSA21) [1].

Children with DS have an increased prevalence of overweight/obesity secondary to several interrelated physiological and behavioral factors [2]. They also have a high prevalence of obesity-related cardiometabolic comorbidities, add to that obesity may hinder the care of individuals with DS, and implicated in the poor quality of life [2,3].

The term "Metabolic Syndrome" (MetS) have been proposed to describe the clustering of cardiometabolic risk factors (CMRFs), including centeral adiposity, hypertension, dyslipidemia and/or glycemic dysregulation including impaired fasting blood glucose (FBG) or type 2 diabetes mellitus. MetS is a convient clinical tool for identification of individuals at risk of developing obesity-related cardiometabolic adverse outcomes [4].

The pathophysiology of MetS is complex and not completely clarified. In this context, adipose tissue has been described as an endocrine gland producing an imbalance between pro-and anti-inflammatory cytokines that elicits a state of low-grade systemic chronic inflammation that is closely correlate with insulin resistance $[5,6]$.

Adiponectin is one of the most studied adipocytokines that is secreted mainly by differentiated adipocytes and regulates metabolic homeostasis particularly improving insulin sensitivity. In addition, it has anti-atherogenic, anti-inflammatory, anti-apoptotic and cardioprotective characteristics $[7,8]$.

Paradoxically, in several pediatric studies, adiponectin levels were lower in obese children compared with normal-weight children, and even lower in obese children with MetS compared to those without $[9,10]$. However, data concerning serum adiponectin level in DS children with obesity are limited.

Therefore, we aimed to explore for the first time whether body adiposity indicators, the frequency of MetS and its components, serum adiponectin and insulin resistance indicies as well as the validity of serum adiponectin as a biomarker for identification of MetS are different in prepubertal "obese-DS" children compared to age-, sex-and BMI-Z-score-matched "obese-control" children.

\section{Methods}

This is cross-sectional study conducted during the period between January 2019 and June 2020 and included 150 prepubertal children (6-11 years) classified into three groups; obese-DS $(n=50)$, obesecontrol $(n=50)$ and normal weight-control $(n=50)$. The study was approved by the local Ethics Committee of Mansoura Faculty of Medicine-Institutional Research Board (Code No. R.20.07.923).

Informed written consent was obtained from parents of all participants. 
Obese children were recruited sequentially during their routine visits at Pediatric Endocrinology Outpatients Clinic at Mansoura University Children's Hospital, Mansoura, Egypt. All participants were of the same ethnicity (Caucasian). All DS cases were full trisomy 21 caused by chromosomal nondisjunction. Normal weight-control children were recruited from a primary school at the same locality. Overall, participants belong to middle-class families and none reported participation in organized physical activity. All participants have normal thyroid profile. Exclusion criteria include; children had syndromic or secondary obesity, those suffering from chronic comorbidities, or receiving medication known to affect the study variables.

\section{Clinical evaluation}

A trained nurse measured weight and height of participants according to standardized techniques. Body mass index (BMI) was calculated as weight divided by squared height $\left(\mathrm{kg} / \mathrm{m}^{2}\right)$. Waist circumference (WC), an indicator for central (abdominal) obesity, was measured midway between costal margin and iliac crest at the end of normal expiration. For all participants, height and BMI Z-scores were calculated using reference data for Egyptian children and adolescents [11].

Given that the characteristic phenotype of individuals with DS as having lower stature, the use of absolute BMI values may lead to a bias in assessing the nutritional status in individuals with DS if compared to peers of same chronological age [12]. Therefore, in short-for-age obese-DS children whose height-for-age Z-scores <-2SD, BMI Z-scores were adjusted for height-age (i.e. the age at which the height of a child is at the 50th percentile on height-for-age growth curve) [13].

According to the 2007 WHO BMI standard deviations (SDs) criteria [14], obesity was defined as BMI Zscore exceeds $+2 \mathrm{SD}$. Children with obesity were further classified based on the percentage of BMI above the 95th BMI percentile into three obesity classes; moderate obesity (\%BMI $\geq 100 \%)$; severe obesity $(\% \mathrm{BMI} \geq 120 \%)$, morbid obesity (\%BMI $\geq 140 \%)$ [15].

Systolic and diastolic blood pressure (SBP/DBP) measurements were obtained using conventional mercury sphygmomanometer following standard technique [16]. Pubertal development was determined in all participants using Tanner classifications. For the purpose of the study, we specifically included prepubertal children only to investigate the study variables independent of the impact of sex steroids.

\section{Body composition evaluation:}

Body composition measurements were obtained by bioimpedance technique using Tanita BC-418MA body composition analyzer (Tanita Corp., Tokyo, Japan). Body adiposity indicators include percentage of total body fat (\%BF), total body-fat mass (FM; kg), trunk-FM ( $\mathrm{kg})$, a marker of central adiposity, and appendicular-FM $(\mathrm{kg})$ as a sum of the FM in the four limbs that reflect peripheral fat distribution. Trunk FM to appendicular FM ratio was calculated.

\section{Biochemical evaluation:}


Blood samples were collected in the morning, after a 12-hour overnight fast and centrifuged, then sera were stored at $-20^{\circ} \mathrm{C}$ until analysis. Fasting lipid profile including; triglycerides was measured by colorometric kit supplied spinreact (Girona, Spain), and high-density lipoprotein cholesterol (HDL-C) was measured by colorometric kit supplied by Human Diagnostics (Wiesbaden, Germany). Serum adiponectin was determined ELISA using AviBion Human Adiponectin (Acrp30) commercial kits (Orgenium Laboratories Business Unit, Finland). Serum insulin was measured by quantitative sandwich ELISA technique using Human Insulin Kit (ab200011) (abcam, USA).

Insulin resistance was assessed by Homeostasis model assessment of insulin resistance (HOMA-IR) using this formula: HOMA-IR = FBG $(\mathrm{mg} / \mathrm{dL}) \times$ Fasting Insulin $(\mu \mathrm{U} / \mathrm{ml}) / 405$. A HOMA-IR value greater than 2.5 was the cut-off point to determine insulin resistance in prepubertal children that corresponds to the 90th percentile of healthy children in previous studies [17]. A fasting serum insulin levels $>15 \mu \mathrm{U} / \mathrm{ml}$ has been suggested to be an alternative for evaluating insulin resistance [18].

\section{Definition of metabolic syndrome:}

Obese children were classified as having Mets if they had at least three of the following five components according to Adult Treatment Panel III (ATP III) criteria modified for the pediatric age group [19]; (1) central adiposity (WC $\geq 90$ th percentile for age and gender); (2) FBG $\geq 100 \mathrm{mg} / \mathrm{dL}(5.6 \mathrm{mmol} / \mathrm{L})$; (3) triglycerides $\geq 150 \mathrm{mg} / \mathrm{dL}$ (1.7 mmol/L); (4) HDL-C $\leq 40 \mathrm{mg} / \mathrm{dL}$ (1.03 mmol/L); and (5) SBP and/or DBP $\geq 90$ th percentile for age, gender and height percentile.

\section{Statistical analysis}

All statistical analyses were performed using SPSS software package version 25.0. Categorical variables were presented as percentages and compared by Chi-square test. Continuous variables were presented as median and interquartile range (IQR) (1st quartile-3rd quartile). Mann-Whitney $\mathrm{U}$ test was used to compare medians of two groups. Kruskal-Wallis analysis used to compare medians of three groups followed by Dunn's test to detect pair-wise comparison. Spearman`s rank-order correlation was applied to determine the strength and direction of the linear relationship between adiponectin and CMRFs. The variables found to be significantly correlated in univariate regression analysis were introduced in multiple regression analysis using adiponectin as a dependent variable.

Receiver operator characteristic (ROC) curves were constructed to evaluate the validity of serum adiponectin as a biomarker for identification of MetS in DS children compared to matched obese-control. The results were expressed as areas under the curves (AUC) and $95 \%$ confidence intervals (CI) and the optimal adiponectin cut-off values for the diagnosis of MetS with relevant specificity and sensitivity were considered at the maximum of Youden index (sensitivity + specificity - 1). The AUCs of obesity-groups were compared using Medcalc statistical software version 19.6.1. Statistical significance was set at $P<$ 0.05 .

\section{Results}


General, anthropometric, body adiposity and biochemical characteristics of the study groups are summarized in Table 1. The study groups were age-and sex-matched $(P>0.05)$. As expected, obesitygroups (obese-DS and obese-control) had significantly higher median values of SBP $(P=0.034)$, BMI Zscores $(P<0.001), W C(P<0.001)$, and body adiposity parameters compared to normal weight-control group. Moreover, significantly higher FBG, fasting insulin, HOMA-IR, and triglycerides and significantly lower adiponectin levels were observed in obesity-groups compared to normal weight-control $(P<0.001)$, while HDL-C was significantly lower in only obese-DS compared to normal weight-control $(P=0.001)$ (Table 1). 
Table 1

General, anthropometric, body composition, and biochemical characteristics of the study groups

\begin{tabular}{|c|c|c|c|c|c|}
\hline & & $\begin{array}{l}\text { Obese-DS } \\
(n=50)\end{array}$ & $\begin{array}{l}\text { Obese- } \\
\text { control } \\
(n=50)\end{array}$ & $\begin{array}{l}\text { Normal } \\
\text { weight-Control } \\
(n=50)\end{array}$ & P-value \\
\hline \multicolumn{2}{|l|}{ Age (years) } & $\begin{array}{l}9.0(8.5- \\
9.9)\end{array}$ & $\begin{array}{l}8.5(8.0- \\
10.5)\end{array}$ & $9.3(7.0-11.0)$ & 0.073 \\
\hline \multirow[t]{2}{*}{ Sex } & Male & $31(62 \%)$ & $30(60 \%)$ & $27(54 \%)$ & \multirow[t]{2}{*}{0.712} \\
\hline & Female & $19(38 \%)$ & $20(40 \%)$ & $23(46 \%)$ & \\
\hline \multicolumn{2}{|c|}{ Systolic blood pressure (mmHg) } & $\begin{array}{l}97.7(85- \\
115)\end{array}$ & $\begin{array}{l}95.2(90- \\
110)\end{array}$ & $85.6(70-105)$ & $0.034^{\mathrm{bc}}$ \\
\hline \multicolumn{2}{|c|}{ Diastolic blood pressure $(\mathrm{mmHg})$} & $\begin{array}{l}66.5(55- \\
70)\end{array}$ & $\begin{array}{l}62.5(50- \\
70)\end{array}$ & $55.7(40-65)$ & 0.188 \\
\hline \multirow[t]{3}{*}{$\begin{array}{l}\text { Anthropometric } \\
\text { parameters }\end{array}$} & Height Z-score & $\begin{array}{l}-1.07 \\
(-1.96- \\
0.32)\end{array}$ & $\begin{array}{l}0.62 \\
(-0.62- \\
0.85)\end{array}$ & $\begin{array}{l}0.29(-0.83- \\
0.14)\end{array}$ & $0.001^{\mathrm{ab}}$ \\
\hline & BMI Z-score & $\begin{array}{l}4.8(3.7- \\
5.2)\end{array}$ & $\begin{array}{l}4.5(3.3- \\
4.8)\end{array}$ & $\begin{array}{l}0.38(-0.58- \\
0.6)\end{array}$ & $\begin{array}{l}<.001^{b c} \\
0\end{array}$ \\
\hline & WC (cm) & $\begin{array}{l}97.7(81.5- \\
105)\end{array}$ & $\begin{array}{l}86.5 \\
(78.0-90)\end{array}$ & $\begin{array}{l}63.0(58- \\
67.5)\end{array}$ & $\begin{array}{l}<.001^{\mathrm{abc}} \\
\end{array}$ \\
\hline \multirow[t]{3}{*}{$\begin{array}{l}\text { Body adiposity } \\
\text { parameters }\end{array}$} & Fat \% & $\begin{array}{l}38.3(30.2- \\
40.7)\end{array}$ & $\begin{array}{l}31.9 \\
(28.7- \\
36.4)\end{array}$ & $\begin{array}{l}18.6(16.6- \\
20.9)\end{array}$ & $\begin{array}{l}< \\
0.001^{a b c}\end{array}$ \\
\hline & $\mathrm{FM}(\mathrm{kg})$ & $\begin{array}{l}21.9(20.3- \\
27.1)\end{array}$ & $\begin{array}{l}17.7 \\
(12.8- \\
23.5)\end{array}$ & $4.9(4.3-5.8)$ & $\begin{array}{l}<.001^{\mathrm{abc}} \\
\end{array}$ \\
\hline & Trunk FM (kg) & $\begin{array}{l}11.1(9.7- \\
12.6)\end{array}$ & $\begin{array}{l}7.9(5.8- \\
10.9)\end{array}$ & $1.7(1.3-2.3)$ & $\begin{array}{l}<.001^{\mathrm{abc}} \\
\end{array}$ \\
\hline
\end{tabular}

All data presented as median and IQR (1st quartile - 3rd quartile) except sex presented as frequency number (\%)

Bold P-value reflect significant difference

a; Comparison between obese-DS and obese-control.

b; Comparison between obese-DS and normal weight-control.

c; Comparison between obese-control and normal weight-control

BMI: Body mass index; DS: Down syndrome; FM: Fat mass; FBG: Fasting blood glucose; HOMA-IR:

Homeostasis model assessment of insulin resistance; HDL-C: High density lipoprotein-cholesterol; TG:

Triglycerides; WC: Waist circumference; 


\begin{tabular}{|c|c|c|c|c|c|}
\hline & & $\begin{array}{l}\text { Obese-DS } \\
(n=50)\end{array}$ & $\begin{array}{l}\text { Obese- } \\
\text { control } \\
(n=50)\end{array}$ & $\begin{array}{l}\text { Normal } \\
\text { weight-Control } \\
(n=50)\end{array}$ & P-value \\
\hline & $\begin{array}{l}\text { Appendicular FM } \\
(\mathrm{kg})\end{array}$ & $\begin{array}{l}10.2(8.9- \\
13.0)\end{array}$ & $\begin{array}{l}9.0(7.1- \\
12.9)\end{array}$ & $3.3(2.9-4.9)$ & $\begin{array}{l}<.001^{b c} \\
\end{array}$ \\
\hline & $\begin{array}{l}\text { Trunk/Appendicular } \\
\text { FM ratio }\end{array}$ & $\begin{array}{l}1.1(0.96- \\
1.2)\end{array}$ & $\begin{array}{l}0.82 \\
(0.75- \\
0.91)\end{array}$ & $\begin{array}{l}0.53(0.36- \\
0.66)\end{array}$ & $<0.001^{\mathrm{abc}}$ \\
\hline \multirow[t]{6}{*}{$\begin{array}{l}\text { Biochemical } \\
\text { parameters }\end{array}$} & $\mathrm{FBG}(\mathrm{mg} / \mathrm{dL})$ & $\begin{array}{l}100(92- \\
105)\end{array}$ & $\begin{array}{l}98(90- \\
102)\end{array}$ & $80(74-85)$ & $\begin{array}{l}<.001^{b c} \\
\end{array}$ \\
\hline & Insulin $(\mu \mathrm{U} / \mathrm{ml})$ & $\begin{array}{l}23.1(12.8- \\
28.7)\end{array}$ & $\begin{array}{l}15.5(7.9- \\
24.9)\end{array}$ & $6.6(4.5-7.8)$ & $\begin{array}{l}<.001^{\mathrm{abc}} \\
\end{array}$ \\
\hline & HOMA-IR & $\begin{array}{l}8.7(3.1- \\
10.2)\end{array}$ & $\begin{array}{l}5.2(1.8- \\
9.7)\end{array}$ & $1.3(0.96-1.6)$ & $\begin{array}{l}< \\
0.001^{a b c}\end{array}$ \\
\hline & $\mathrm{HDL}-\mathrm{C}(\mathrm{mg} / \mathrm{dL})$ & $\begin{array}{l}47.5(40- \\
50)\end{array}$ & $\begin{array}{l}52.5(45- \\
55)\end{array}$ & $51(48-65)$ & $0.001^{\mathrm{ab}}$ \\
\hline & $\begin{array}{l}\text { Triglycerides } \\
(\mathrm{mg} / \mathrm{dL})\end{array}$ & $\begin{array}{l}148.5 \\
(107.5- \\
172)\end{array}$ & $\begin{array}{l}130(77- \\
157.8)\end{array}$ & $79(65-95)$ & $\begin{array}{l}<.001^{a b c} \\
\end{array}$ \\
\hline & $\begin{array}{l}\text { Adiponectin } \\
\text { (ng/ml) }\end{array}$ & $\begin{array}{l}3.2(2.7- \\
5.7)\end{array}$ & $\begin{array}{l}5.3(4.2- \\
8.3)^{-}\end{array}$ & $7.4(5.9-10.8)$ & $\begin{array}{l}< \\
0.001^{a b c}\end{array}$ \\
\hline \multicolumn{6}{|c|}{$\begin{array}{l}\text { All data presented as median and IQR (1st quartile - 3rd quartile) except sex presented as frequency } \\
\text { number (\%) }\end{array}$} \\
\hline \multicolumn{6}{|c|}{ Bold P-value reflect significant difference } \\
\hline \multicolumn{6}{|c|}{ a; Comparison between obese-DS and obese-control. } \\
\hline \multicolumn{6}{|c|}{ b; Comparison between obese-DS and normal weight-control. } \\
\hline \multicolumn{6}{|c|}{ c; Comparison between obese-control and normal weight-control } \\
\hline \multicolumn{6}{|c|}{$\begin{array}{l}\text { BMI: Body mass index; DS: Down syndrome; FM: Fat mass; FBG: Fasting blood glucose; HOMA-IR: } \\
\text { Homeostasis model assessment of insulin resistance; HDL-C: High density lipoprotein-cholesterol; TG: } \\
\text { Triglycerides; WC: Waist circumference; }\end{array}$} \\
\hline
\end{tabular}

Considering obesity-groups, although the two groups were matched for BMI Z-score ( $P=0.707)$, obese-DS group had significantly higher WC $(P=0.027)$, \%BF $(P=0.036), F M(P=0.001)$, trunk-FM $(P<0.001)$, and trunk/appendicular FM ratio $(\mathrm{P}<0.001)$ compared to obese-control group. In terms of biochemical parameters, obese-DS children had significantly higher median values of fasting insulin $(P=0.040)$, HOMA-IR $(P=0.038)$, and triglycerides $(P=0.029)$, and significantly lower median values of HDL-C $(P=$ $0.001)$ and serum adiponectin $(P=0.004)$ compared to obese-control (Table 1). 
As depicted in Fig. 1, Adiponectin levels were significantly lower in obese-DS compared to obese-control in moderate obesity $(P<0.001)$ and morbid obesity $(P=0.001)$ classes only. Within obese-DS, serum adiponectin was significantly lower in moderate obesity compared to severe obesity classes $(P=0.001)$ and in severe obesity compared to morbid obesity classes $(P=0.001)$, while within obese-control, serum adiponectin was significantly lower in moderate obesity compared to severe obesity classes $(P=0.001)$, but no significant difference was detected between severe obesity and morbid obesity classes $(P=$ $0.178)$.

Figure 2 demonstrates that the prevalence of MetS was significantly higher in obese-DS (56\%) compared to obese-control $(34 \%)(P=0.016)$. Central adiposity ( $W C \geq 90$ th percentile) was the most prevalent alteration in MetS components in both obesity-groups, that was significantly higher in obese-DS compared to obese-control $(78 \%$ vs. $56 \% ; P=0.019)$. Moreover, the frequencies of the remaining altered MetS components were also higher in obese-DS compared to obese-control, but did not reach significant levels $(P>0.05)$. Children with "elevated SBP" were very few in both obesity-groups $(16 \%$ of obese-DS and $10 \%$ of obese-control) and virtually no "elevated DBP" was detected in obesity-groups.

The frequencies insulin resistance indices were significantly higher in obese-DS compared to obesecontrol including; hyper-insulinemia (fasting insulin $\geq 15 \mu \mathrm{U} / \mathrm{ml}$ ) and HOMA-IR value of $>2.5(P=0.023$ and $\mathrm{P}=0.017$, respectively).

In the context of MetS, obese-DS children with MetS were significantly younger in age $(P=0.019)$ and exhibited significantly higher median values of WC $(P=0.037)$, FM $(P=0.033)$, trunk-FM $(P=0.004)$, trunk/appendicular FM ratio $(P<0.001)$, fasting insulin $(P<0.001)$, and HOMA-IR $(P=0.007)$ and exhibited significantly lower median adiponectin value $(P=0.010)$ than obese-control children with MetS (Table 2). 
Table 2

General, anthropometric, body adiposity, and biochemical characteristics of children who had metabolic syndrome (MetS+) within obesity groups

\begin{tabular}{|c|c|c|c|c|}
\hline & & $\begin{array}{l}\text { Obese-DS } \\
\text { MetS+ } \\
(n=28)\end{array}$ & $\begin{array}{l}\text { Obese-control } \\
\text { MetS+ } \\
(n=16)\end{array}$ & $\begin{array}{l}P \text { - } \\
\text { value }\end{array}$ \\
\hline Age (years) & & $8.0(7.0-10.5)$ & $10.0(9.0-11)$ & $0.019 *$ \\
\hline Systolic blood pl & $\mathrm{nmHg})$ & $\begin{array}{l}105.2(95- \\
120)\end{array}$ & $99.5(90-120)$ & 0.087 \\
\hline Diastolic blood $\mathrm{p}$ & $\mathrm{mmHg})$ & $63.9(60-85)$ & $65.4(65-85)$ & 0.787 \\
\hline $\begin{array}{l}\text { Anthropometric } \\
\text { parameters }\end{array}$ & Height Z-score & $\begin{array}{l}-1.03(-1.54- \\
0.76)\end{array}$ & $0.55(-0.82-1.18)$ & 0.045 \\
\hline & BMI Z-score & $5.7(4.5-6.5)$ & $4.8(4.1-5.2)$ & 0.215 \\
\hline & WC (cm) & $\begin{array}{l}99.3(88.3- \\
105)\end{array}$ & $92.0(87-97)$ & $0.037 *$ \\
\hline $\begin{array}{l}\text { Body adiposity } \\
\text { parameters }\end{array}$ & Fat $\%$ & $\begin{array}{l}36.8(32.1- \\
41.2)\end{array}$ & $35.5(26.3-40.5)$ & 0.276 \\
\hline & $\mathrm{FM}(\mathrm{kg})$ & $\begin{array}{l}24.7(21.6- \\
28.8)\end{array}$ & $22.0(12.8-25.7)$ & $0.033^{*}$ \\
\hline & Trunk FM (kg) & $\begin{array}{l}11.8(10.2- \\
14.7)\end{array}$ & $9.2(6.2-11.6)$ & $0.004^{*}$ \\
\hline & Appendicular FM (kg) & $\begin{array}{l}12.7(9.5- \\
13.6)\end{array}$ & $11.5(7.3-14.0)$ & 0.232 \\
\hline & $\begin{array}{l}\text { Trunk/Appendicular FM } \\
\text { ratio }\end{array}$ & $\begin{array}{l}0.97(0.95- \\
1.3)\end{array}$ & $0.82(0.75-0.88)$ & ¿.001* \\
\hline $\begin{array}{l}\text { Biochemical } \\
\text { parameters }\end{array}$ & $\mathrm{FBG}(\mathrm{mg} / \mathrm{dL})$ & $\begin{array}{l}102(95.5- \\
108)\end{array}$ & $99(90-102)$ & 0.105 \\
\hline & Insulin $(\mu \mathrm{U} / \mathrm{ml})$ & $\begin{array}{l}28.9(23.8- \\
30.0)\end{array}$ & $20.3(11.1-26.3)$ & <. $001 *$ \\
\hline & HOMA-IR & $\begin{array}{l}10.8(6.8- \\
17.8)\end{array}$ & $7.5(2.7-9.4)$ & $0.007 *$ \\
\hline & $\mathrm{HDL}-\mathrm{C}(\mathrm{mg} / \mathrm{dL})$ & $46.7(40-50.0)$ & $48.0(45-55)$ & 0.285 \\
\hline
\end{tabular}

All data presented as median and IQR (1st quartile - 3rd quartile)

Bold P-value reflect significant difference

BMI: Body mass index; DS: Down syndrome; FM: Fat mass; FBG: Fasting blood glucose; HOMA-IR: Homeostasis model assessment of insulin resistance; HDL-C: High density lipoprotein-cholesterol; MetS, metabolic syndrome; WC: Waist circumference; 


\begin{tabular}{|c|c|c|c|}
\hline & $\begin{array}{l}\text { Obese-DS } \\
\text { MetS+ } \\
(n=28)\end{array}$ & $\begin{array}{l}\text { Obese-control } \\
\text { MetS+ } \\
(n=16)\end{array}$ & $\begin{array}{l}P- \\
\text { value }\end{array}$ \\
\hline Triglycerides (mg/dL) & $\begin{array}{l}155(120- \\
176.5)\end{array}$ & $135(77.3-163)$ & $0.035 *$ \\
\hline Adiponectin (ng/ml) & $3.2(1.8-4.0)$ & $4.5(3.4-5.5)$ & 0.010 * \\
\hline \multicolumn{4}{|c|}{ All data presented as median and IQR (1st quartile - 3rd quartile) } \\
\hline \multicolumn{4}{|l|}{ Bold P-value reflect significant difference } \\
\hline \multicolumn{4}{|c|}{$\begin{array}{l}\text { BMI: Body mass index; DS: Down syndrome; FM: Fat mass; FBG: Fasting blood glucose; HOMA-IR: } \\
\text { Homeostasis model assessment of insulin resistance; HDL-C: High density lipoprotein-cholesterol; } \\
\text { MetS, metabolic syndrome; WC: Waist circumference; }\end{array}$} \\
\hline
\end{tabular}

Table 3 demonstrates the results of correlation analysis. In both obesity-groups, serum adiponectin was inversely correlated with age, BMI, WC, total-FM, trunk-FM, FBG, fasting serum insulin, HOMA-IR, and triglycerides. In obese-DS only, serum adiponectin was inversely correlated with trunk/appendicular FM ratio and was positively correlated with HDL-C. 
Table 3

correlations analysis of serum adiponectin with cardiometabolic risk factors in obesity groups

\begin{tabular}{|c|c|c|c|c|}
\hline & Obese- & & Obeser & \\
\hline & $\mathbf{r}$ & $\mathbf{P}$ & $\mathbf{r}$ & $\mathbf{P}$ \\
\hline Age (years) & -0.600 & $<0.001$ & -0.490 & $<0.001$ \\
\hline BMI $\left(\mathrm{Kg} / \mathrm{m}^{2}\right)$ & -0.858 & $<0.001$ & -0.865 & $<0.001$ \\
\hline WC (cm) & -0.872 & $<0.001$ & -0.684 & $<0.001$ \\
\hline Fat $\%$ & -0.157 & 0.276 & -0.228 & 0.257 \\
\hline FM (Kg) & -0.827 & $<0.001$ & -0.607 & $<0.001$ \\
\hline Trunk FM & -0.509 & $<0.001$ & -0.773 & $<0.001$ \\
\hline Trunk/Appendicular FM ratio & -0.457 & 0.017 & -0.207 & 0.148 \\
\hline FBG (mg/dl) & -0.360 & 0.010 & -0.304 & 0.032 \\
\hline Serum insulin $(\mu \mathrm{U} / \mathrm{ml})$ & -0.679 & $<0.001$ & -0.555 & $<0.001$ \\
\hline HOMA-IR & -0.788 & $<0.001$ & -0.802 & $<0.001$ \\
\hline $\mathrm{HDL}-\mathrm{C}(\mathrm{mg} / \mathrm{dL})$ & 0.434 & 0.002 & 0.260 & 0.071 \\
\hline $\mathrm{TG}(\mathrm{mg} / \mathrm{dL})$ & -0.316 & 0.026 & -0.475 & $<0.001$ \\
\hline r: Spearman`s rank-order corre & & & & \\
\hline Bold P-value reflect significan & & & & \\
\hline $\begin{array}{l}\text { BMI: Body mass index; DS: Dc } \\
\text { Homeostasis model assessm } \\
\text { Triglycerides; WC: Waist circur }\end{array}$ & $\begin{array}{l}\text { M: Fat n } \\
\text { istance; }\end{array}$ & $\begin{array}{l}\text { BG, fast } \\
\text { High d }\end{array}$ & $\begin{array}{l}\text { ood gluc } \\
\text { lipoprote }\end{array}$ & $\begin{array}{l}\text { HOMA-IR: } \\
\text { olesterol; TG: }\end{array}$ \\
\hline
\end{tabular}

Multiple regression analysis of adiponectin in obesity-groups revealed that the significance was only maintained between adiponectin and age in both obese-DS $(\beta=0.495 ; P=0.009)$ and obese-control $(\beta=$ $0.344 ; P=0.034)$ and between adiponectin and WC $(\beta=0.760 ; P=0.033)$, and triglycerides $(\beta=0.474 ; P=$ $0.005)$ in obese-DS only.

Considering the validity of serum adiponectin for diagnosis of MetS in obese-DS, AUC was 0.808 (95\% Cl: $0.672-0.906)$, with cut-off value $\leq 4.8 \mu \mathrm{g} / \mathrm{ml}$ ( $96.43 \%$ sensitivity and $59.09 \%$ specificity), while in obesecontrol, AUC was 0.674 (95\% Cl: $0.505-0.815)$, with cut-off value $\leq 5.5 \mu \mathrm{g} / \mathrm{ml}(76.47 \%$ sensitivity and $57.58 \%$ specificity).

Serum adiponectin seems to perform better for MetS identification in obese-DS than in obese-control, although the pairwise comparison of AUCs between the two groups did not reach a significant level $(P=$ 
0.171) (Fig. 3).

\section{Discussion}

Adiponectin has attracted tremendous scientific interest as a candidate biomarker of MetS in childhood obesity [9, 10, 20,21], and as a therapeutic target for obesity [22], owing to pediatric studies reported that after weight reduction, adiponectin increases with associated improvement in insulin sensitivity $[23,24]$.

It has been hypothesized that DS could be a "metabolic disease", in which trisomy of HSA21 has a key role in altered energy metabolism that is strongly related to dysregulation of insulin and insulin signaling pathways [25]. Moreover, all the body adiposity indicators such as BMI, WC, waist to height ratio, \%BF, and FM were reported to be significantly higher in obese-DS children and adolescents compared to ageand sex-matched normal-weight controls [26-28].

In the current study, obese-DS children exhibited significantly excess body adiposity with profound central fat distribution as indicated by higher WC, trunk-FM, and trunk/appendicular FM ratio in obese-DS compared to age-and BMI Z-score-matched obese-controls which point to the higher risk for MetS in obese-DS.

Practically, the frequency of MetS was significantly higher in the obese-DS (56\%) compared to obesecontrol (34\%). Central adiposity was the most prevalent alteration in MetS components in both obesitygroups, that was significantly higher in obese-DS compared to obese-control (78\% vs. $56 \%)$, while the frequencies of the remaining altered MetS components were also higher in obese-DS compared to obesecontrol, but did not reach significant levels. Interestingly, fasting serum insulin and HOMA-IR values as well as the frequencies of insulin resistance indices including hyperinsulinemia (fasting insulin $\geq 15$ $\mu \mathrm{U} / \mathrm{ml}$ ) and HOMA-IR (>2.5) were significantly higher in obese-DS compared to obese-control.

Considerable progress has been made in the clarification of the central role of insulin resistance as a keyelement linking obesity and CMRFs clustering, and the potential mechanisms leading to insulin resistance development in obese children [29]. Previuos studies in obese adolescents have indicated that insulin resistance is related to a particular centeral fat distribution and ectopic fat accumulation [30, 31]. In this context, obese-DS with MetS were significantly younger in age and exhibited pronounced central fat distribution and higher fasting serum insulin and HOMA-IR values than obese-control with MetS.

Data regarding the circulating adiponectin level in DS children are scarce [26, 32, 33]. Tenneti et al. [32] reported a lower adiponectin levels in normal weight children with DS. Similar findings were detected by Gutierrez-Hervas et al. [26] in adolescents with DS with variable degree of adiposity. Corsi et al. [33] found that adiponectin levels were significantly higher in three different age cohorts of normal-weight DS individuals including children $(n=23$; age $2-14$ years), adults $(n=14$; age $20-50$ years $)$ and elders $(n=$ 13 ; age $>60$ years) compared to healthy controls. Moreover, they reported age-related increments in adiponectin levels among DS individuals, where elders with DS had significantly higher adiponectin levels compared to the younger and middle age counterparts. 
Interestingly, individuals with DS represent a still unsolved biological/clinical paradox. Although an increment of classical biochemical risk factors for atherosclerosis should induce an elevated risk of atherosclerosis in normal-weight DS individuals, DS has been considered an atheroma-free model [33], with evident low risk of atherosclerosis-related morbidity and mortality in healthy subjects with DS during adulthood and senility [34]. Reasons of this discrepancy remain obscure. Corsi et al. [33] suggested that elevated adiponectin level in healthy adults and elders with DS may play a protective role against atherosclerosis by regulating endothelial activation.

This study showed for the first time that serum adiponectin level was significantly lower in prepubertal obese-DS compared to obese-controls, despite being matched for age-and BMI Z-score. We also detected a decreasing trend in adiponectin concentrations with increasing the severity of obesity in both obesity groups that was more pronounced in obese-DS than in obese-control. Interestingly, obese-DS with MetS also exhibited significantly lower median adiponectin value than obese-control with MetS.

The observed high degree of discordance between obese-DS and matched obese-control in respect to body adiposity indicators, the frequency of MetS and its components, serum adiponectin and insulin resistance indices point to intrinsic idiosyncratic factors other than traditional risk factors may contribute to the increased risk for cardiometabolic disorders in subjects with DS that are closely related to trisomy of HSA21.

As to the association between serum adiponectin level and CMRFs, serum adiponectin was inversely correlated with age, BMI, WC, total-FM, trunk-FM, FBG, fasting serum insulin, HOMA-IR, and triglycerides and was positively correlated with HDL-C in obese-DS. These associations might related to the effect of adiponectin on metabolic homeostasis whereas adiponectin enhances fatty acids and triglycerides catabolism, promotes glucose uptake by skeletal muscle and increasing serum HDL-C level by its action on hepatic lipase activity $[7,8]$.

Interestingly, central obesity was the predominant CMRFs for MetS and strongly correlated with low adiponectin levels, thus evident needs to motivate individuals with DS to participate and adherence to regular and consistent exercise programs to reduce abdominal obesity as prophylactic and as a treatment for MetS.

Previous studies conducted on non-DS children and adolescents with obesity reported variable and nonconsistent associations between adiponectin level and various CMRFs [35-38]. It has been presumed that the variation in genetic backgrounds in different ethnicity are major factors in determining the level of adiponectin expression and its association with various CMRFs [39, 40].

For clinical practice, we explored the validity of serum adiponectin level for the diagnosis of MetS in obese-groups, the results of ROC curve analysis showed that adiponectin seems to perform better in the diagnosis of MetS in obese-DS (AUC = 0.808) than in obese-control (AUC=674), with lower cut-off value in obese-DS compared to obese-control ( $4.8 \mu \mathrm{g} / \mathrm{ml}$ vs. $5.5 \mu \mathrm{g} / \mathrm{ml}$, respectively). Our results were comparable to the reports from studies conducted on non-DS obese children and adolescents of different 
ethnicity. The optimal cut-off values of serum adiponectin for diagnosis of MetS among Japanease children was $6.65 \mu \mathrm{g} / \mathrm{ml}(\mathrm{AUC}=0.672)$ [41], while among Chinese children was $4.5 \mathrm{ug} / \mathrm{ml}$ for boys (AUC = $0.697)$ and was $5.2 \mathrm{ug} / \mathrm{ml}$ for girls $(A U C=0.689)$ [42], and among Italian children was $10.9 \mathrm{mg} / \mathrm{dl}(\mathrm{AUC}=$ 0.72) [43].

The principal limitation of the current study is the cross-sectional design, which precludes us to identify the causal direction between adiponectin concentrations and CMRFs in DS children. However, as strength, our study is the first to explore body adiposity, MetS components, insulin resistance indices, and serum adiponectin level among prepubertal obese-DS children in comparison to age-and BMI-matched obesecontrols. Our results collectively suggest that low adiponectin level seems to be an important mediator in the development of MetS in DS children as have been suggested in individuals without DS [44].

\section{Conclusions}

The current study highlights for the first time that pre-pubertal obese-DS children displayed excess body adiposity with pronounced central fat distribution, atherogenic lipid profile and higher insulin resistance as well as higher prevalence of MetS and its altered components compared to matched obese-control. Serum adiponectin level was significantly lower in obese-DS children than in obese-controls and was even lower in obese-DS with MetS compared to obese-control with MetS. Pronounced decrease in adiponectin values with increasing the severity of obesity were detected in obese-DS children. Adiponectin exhibited strong correlations with body adiposity, several MetS components and HOMA-IR and performed better as a potential biomarker for identification of MetS among obese-DS children than in obese-controls.

\section{Recommendations}

Although adiponectin is not a measure routinely done and is an expensive assay that preclude its use in clinical settings at this time, our results pave the way for future prospective studies to explore the impact of different cytogenetic types, and pubertal stages on CMRFs and serum adiponectin and to evaluate the potential use of adiponectin as a therapeutic target for MetS in high-risk populations childhood obesity. In clinical practice, our results reinforce early counseling for DS children regarding healthy nutrition and active lifestyle to prevent early-onset adiposity and annual screening for CMRFs in youths with DS, particularly with current evident increase in their life expectancy.

\section{Abbreviations}

CMRFs, cardiometabolic risk factors

DBP, diastolic BP

DS, Down syndrome 
HOMA-IR, Homeostasis-Model-Assessment of Insulin-Resistance

HSA21, human chromosome 21

ATP III, Adult Treatment Panel III

MetS, metabolic syndrome

SBP, systolic BP

WC, waist-circumference.

\section{Declarations}

Funding source: The authors did not receive funding support from any agency or organization for the research, authorship, and/or publication of the submitted work.

Financial interests: The authors have no relevant financial or non-financial interests relevant to the submitted work to disclose.

Conflicts of interest: The authors have no conflicts of interest relevant to the content of this article to declare.

Ethical approval: The study protocol was approved by the Ethics Committee of Mansoura Faculty of Medicine-Institutional Research Board (Code No. R.20.07.923). The procedures used in this study adhere to the tenets of the Declaration of Helsinki.

Consent to participate: Informed consent was obtained from the parents of all individual participant included in the study.

\section{Consent for publication: N/A}

Data and material availability: The data that support the findings of this study are available from the corresponding author upon reasonable request.

\section{Code availability: N/A}

Author's contribution: Sohier Yahia and Nanees Salem conceived the main study idea and design, Nanees Salem and Rowayda Ramadan collected clinical data, Reham El-Farahaty performed biochemical analysis, Abdel-Hady EL-Gilany and Rasha Shoaib analyzed data, Nanees Salem wrote the first draft of manuscript; all authors involved in data interpretation, manuscript revision and editing and literature search and had final approval of the submitted version.

Acknowledgements: We are grateful to the children who participated in this study as well as their parents and families. 


\section{References}

1. Hickey F, Hickey E, Summar KL (2012) Medical update for children with Down syndrome for the pediatrician and family practitioner. Adv. Pediatr. 59:137-157.

2. O' Shea M, O' Shea C, Gibson L, Leo J, Carty C (2018) The prevalence of obesity in children and young people with Down syndrome. J Appl Res Intellect Disabil. 31(6):1225-1229.

3. Bertapelli F., Petetti K., Agiovlasitis S., Guerra-Junior G (2016) Overweight and obesity in children and adolescents with Down syndrome-prevalence, determinants, consequences, and interventions: a literature review. Res. Dev. Disabil. 57:181-92.

4. Magge SN, Goodman E, Armstrong SC, AAP COMMITTEE ON NUTRITION, SECTION ON ENDOCRINOLOGY, SECTION ON OBESITY (2017) The Metabolic Syndrome in Children and Adolescents: Shifting the Focus to Cardiometabolic Risk Factor Clustering. Pediatrics. 140(2):e20171603

5. Valle M, Martos R, Gascón F, Cañete R, Zafra MA, Morales R (2005) Low-grade systemic inflammation, hypoadiponectinemia and a high concentration of leptin are present in very young obese children, and correlate with metabolic syndrome. Diabetes Metab. 31(1):55-62.

6. Ebert T, Gebhardt C, Scholz M, Wohland T, Schleinitz D, Fasshauer M, Blüher M, Stumvoll M, Kovacs P, Tönjes A (2018) Relationship between 12 adipocytokines and distinct components of the metabolic syndrome. J Clinical Endocrinol Metab. 103:1015-23.

7. Choi HM, Doss HM, Kim KS (2020) Multifaceted Physiological Roles of Adiponectin in Inflammation and Diseases. Int. J. Mol. Sci. 21:1219.

8. Stern JH, Rutkowski JM, Scherer PE (2016) Adiponectin, Leptin, and Fatty Acids in the Maintenance of Metabolic Homeostasis through Adipose Tissue Crosstalk. Cell Metab. 23(5):770-784.

9. Calcaterra V, De Amici M, Klersy C, Torre C, Brizzi V, Scaglia F, Albanesi M, Albertini R, Allais B, Larizza D (2009) Adiponectin, IL-10 and metabolic syndrome in obese children and adolescents. Acta Biomed. 80:117-23.

10. Klünder-Klünder M, Flores-Huerta S, García-Macedo R, Peralta-Romero J, Cruz M (2013) Adiponectin in eutrophic and obese children as a biomarker to predict metabolic syndrome and each of its components. BMC Public Health. 30;13:88.

11. Ghalli I, Salah N, Hussien F, Erfan M, El-Ruby M, Mazen I, Sabry M, Abd El-Razik M, Saad M, Hossney S, Ismaail, Abd El-Dayem S (2002) Egyptian growth curves for infants, children and adolescents. In: Satorio A, Buckler JMH, Marazzi N (eds) Crecerenelmondo. Ferring Publisher, Italy (2008).

12. Olivetti Artioli T, Witsmiszyn E, Belo Ferreira A, Franchi Pinto C (2017) Assessing Down syndrome BMI and body composition. Int Med Rev on Down Syndrome 21(2): 23-26

13. Bonthuis M, Jager KJ, Abu-Hanna A, Verrina E, Schaefer F, van Stralen KJ (2013) Application of body mass index according to height-age in short and tall children. PLoS One. 8(8):e72068.

14. de Onis M, Onyango AW, Borghi E, Siyam A, Nishida C, Siekmann J (2007) Development of a WHO growth reference for school-aged children and adolescents. Bull World Health Organ. 85:660-7. 
15. Skinner AC, Perrin EM, Moss LA, Skelton JA (2015) Cardiometabolic risks and severity of obesity in children and young adults. N. Engl. J. Med. 373:1307-1317.

16. Flynn JT, Kaelber DC, Baker-Smith CM, et al; SUBCOMMITTEE ON SCREENING AND MANAGEMENT OF HIGH BLOOD PRESSURE IN CHILDREN (2017) Clinical Practice Guideline for Screening and Management of High Blood Pressure in Children and Adolescents. Pediatrics. 140(3):e20171904.

17. Valerio G, Licenziati MR, lannuzzi A, Franzese A, Siani P, Riccardi G, Rubba P (2006) Insulin resistance and impaired glucose tolerance in obese children and adolescents from Southern Italy. Nutr Metab Cardiovasc Dis.16:279-284.

18. Williams CL, Hayman LL, Daniels SR, Robinson TN, Steinberger J, Paridon S, Bazzarre T (2002) Cardiovascular health in childhood: A statement for health professionals from the Committee on Atherosclerosis, Hypertension, and Obesity in the Young (AHOY) of the Council on Cardiovascular Disease in the Young, American Heart Association. Circulation 106(1):143-60.

19. Steinberger J, Daniels SR, Eckel RH, Hayman L, Lustig RH, McCrindle B, Mietus-Snyder ML; American Heart Association Atherosclerosis, Hypertension, and Obesity in the Young Committee of the Council on Cardiovascular Disease in the Young; Council on Cardiovascular Nursing; and Council on Nutrition, Physical Activity, and Metabolism (2009) Progress and challenges in metabolic syndrome in children and adolescents: a scientific statement from the American Heart Association Atherosclerosis, Hypertension, and Obesity in the Young Committee of the Council on Cardiovascular Disease in the Young; Council on Cardiovascular Nursing; and Council on Nutrition, Physical Activity, and Metabolism. Circulation. 119(4):628-47.

20. Gilardini L, McTernan PG, Girola A, da Silva NF, Alberti L, Kumar S, Invitti C (2006) Adiponectin is a candidate marker of metabolic syndrome in obese children and adolescents. Atherosclerosis 189(2):401-407.

21. Shaibi GQ, Cruz ML, Weigensberg MJ, Toledo-Corral CM, Lane CJ, Kelly LA, Davis JN, Koebnick C, Ventura EE, Roberts CK, Goran MI (2007) Adiponectin independently predicts metabolic syndrome in overweight Latino youth. J Clin Endocrinol Metab. 92(5):1809-1813.

22. Achari AE, Jain SK (2017) Adiponectin, a Therapeutic Target for Obesity, Diabetes, and Endothelial Dysfunction. Int J Mol Sci. 18(6):1321.

23. Cambuli VM, Musiu MC, Incani M, Paderi M, Serpe R, Marras V, Cossu E, Cavallo MG, Mariotti S, Loche S, Baroni MG (2008) Assessment of adiponectin and leptin as biomarkers of positive metabolic outcomes after lifestyle intervention in overweight and obese children. J Clin Endocrinol Metab. 93(8):3051-3057.

24. Martos-Moreno GA, Barrios V, Martinez G, Hawkins F, Argente J (2010) Effect of weight loss on highmolecular weight adiponectin in obese children. Obesity 18(12):2288-2294.

25. Dierssen M, Fructuoso M, Martínez de Lagrán M, Perluigi M, Barone E (2020) Down Syndrome Is a Metabolic Disease: Altered Insulin Signaling Mediates Peripheral and Brain Dysfunctions. Front Neurosci.14:670. 
26. Gutierrez-Hervas A, Gómez-Martínez S, Izquierdo-Gómez R, Veiga OL, Perez-Bey A, Castro-Piñero J, Marcos A (2020) Inflammation and fatness in adolescents with and without Down syndrome: UP \& DOWN study. J Intellect Disabil Res. 64(2):170-179.

27. Gonzalez-Aguero A, Vicente-Rodriguez G, Ara I, Moreno LA, Casajus JA (2011) Accuracy of prediction equations to assess percentage of body fat in children and adolescents with Down syndrome compared to air displacement plethysmography. Res. Dev. Disabil. 32:1764-1769.

28. Loveday SJ, Thompson JM, Mitchell EA (2012) Bioelectrical impedance for measuring percentage body fat in young persons with Down syndrome: validation with dual-energy absorptiometry. Acta Paediatr. 101:e491-e495.

29. Caprio S, Santoro N, Weiss R (2020) Childhood obesity and the associated rise in cardiometabolic complications. Nat Metab. 2(3):223-232.

30. Kursawe R, Eszlinger M, Narayan D, Liu T, Bazuine M, Cali AM, D'Adamo E, Shaw M, Pierpont B, Shulman GI, Cushman SW, Sherman A, Caprio S (2010) Cellularity and adipogenic profile of the abdominal subcutaneous adipose tissue from obese adolescents: association with insulin resistance and hepatic steatosis. Diabetes. 59(9):2288-96.

31. Kursawe R, Caprio S, Giannini C, Narayan D, Lin A, D'Adamo E, Shaw M, Pierpont B, Cushman SW, Shulman GI (2013) Decreased transcription of ChREBP- $\alpha / \beta$ isoforms in abdominal subcutaneous adipose tissue of obese adolescents with prediabetes or early type 2 diabetes: associations with insulin resistance and hyperglycemia. Diabetes. 62(3):837-44.

32. Tenneti N, Dayal D, Sharda S, Panigrahi I, Didi M, Attri SV, Sachdeva N, Bhalla AK (2017) Concentrations of leptin, adiponectin and other metabolic parameters in non-obese children with Down syndrome. J Pediatr Endocrinol Metab. 28;30(8):831-837.

33. Corsi MM, Dogliotti G, Pedroni F, Galliera E, Malavazos AE, Villa R, Chiappelli M, Licastro F (2009) Adipocytokines in Down's syndrome, an atheroma-free model: Role of adiponectin. Arch Gerontol Geriatr. 48(1):106-9.

34. Uppal H, Chandran S, Potluri R (2015) Risk factors for mortality in Down syndrome. J Intellect Disabil Res. 59:873-81.

35. Shafiee G, Ahadi Z, Qorbani M, Kelishadi R, Ziauddin H, Larijani B, Heshmat R (2015) Association of adiponectin and metabolic syndrome in adolescents: the caspian- III study. J Diabetes Metab Disord. 18;14:89.

36. Chu NF, Shen MH, Wu DM, Lai CJ (2005) Relationship between plasma adiponectin levels and metabolic risk profiles in Taiwanese children. Obes Res. 13(11):2014-20.

37. Asayama K, Hayashibe H, Dobashi K, Uchida N, Nakane T, Kodera K, Shirahata A, Taniyama M (2003) Decrease in serum adiponectin level due to obesity and visceral fat accumulation in children. Obes Res. 11(9):1072-9.

38. Zou CC, Liang L, Hong F (2007) Relationship between insulin resistance and serum levels of adiponectin and resistin with childhood obesity. Indian Pediatr. 44(4):275-279. 
39. Morimoto Y, Conroy SM, Ollberding NJ, Kim Y, Lim U, Cooney RV, Franke AA, Wilkens LR, Hernandez BY, Goodman MT, Henderson BE, Kolonel LN, Le Marchand L, Maskarinec G (2014) Ethnic differences in serum adipokine and C-reactive protein levels: the multiethnic cohort. Int $\mathrm{J}$ Obes (Lond). 38(11):1416-22.

40. Zadjali F, Al-Yahyaee S, Hassan MO, Albarwani S, Bayoumi RA (2013) Association of adiponectin promoter variants with traits and clusters of metabolic syndrome in Arabs: family-based study. Gene. 527(2):663-9.

41. Ogawa Y, Kikuchi T, Nagasaki K, Hiura M, Tanaka Y, Uchiyama M (2005) Usefulness of serum adiponectin level as a diagnostic marker of metabolic syndrome in obese Japanese children. Hypertens Res. 28(1):51-57.

42. Li G, Xu L, Zhao Y, Li L, Fu J, Zhang Q, Li N, Xiao X, Li C, Mi J, Gao S, Li M (2017) Leptin-adiponectin imbalance as a marker of metabolic syndrome among Chinese children and adolescents: The BCAMS study. PLoS One. 11;12(10):e0186222.

43. Arrigo T, Chirico V, Salpietro V, Munafò C, Ferraù V, Gitto E, Lacquaniti A, Salpietro C (2013) Highmobility group protein B1: a new biomarker of metabolic syndrome in obese children. Eur $\mathrm{J}$ Endocrinol. 168(4):631-8.

44. Lara-Castro C, Fu Y, Chung BH, Garvey WT (2007) Adiponectin and the metabolic syndrome: mechanisms mediating risk for metabolic and cardiovascular disease. Curr Opin Lipidol. 18(3):26370 .

\section{Figures}




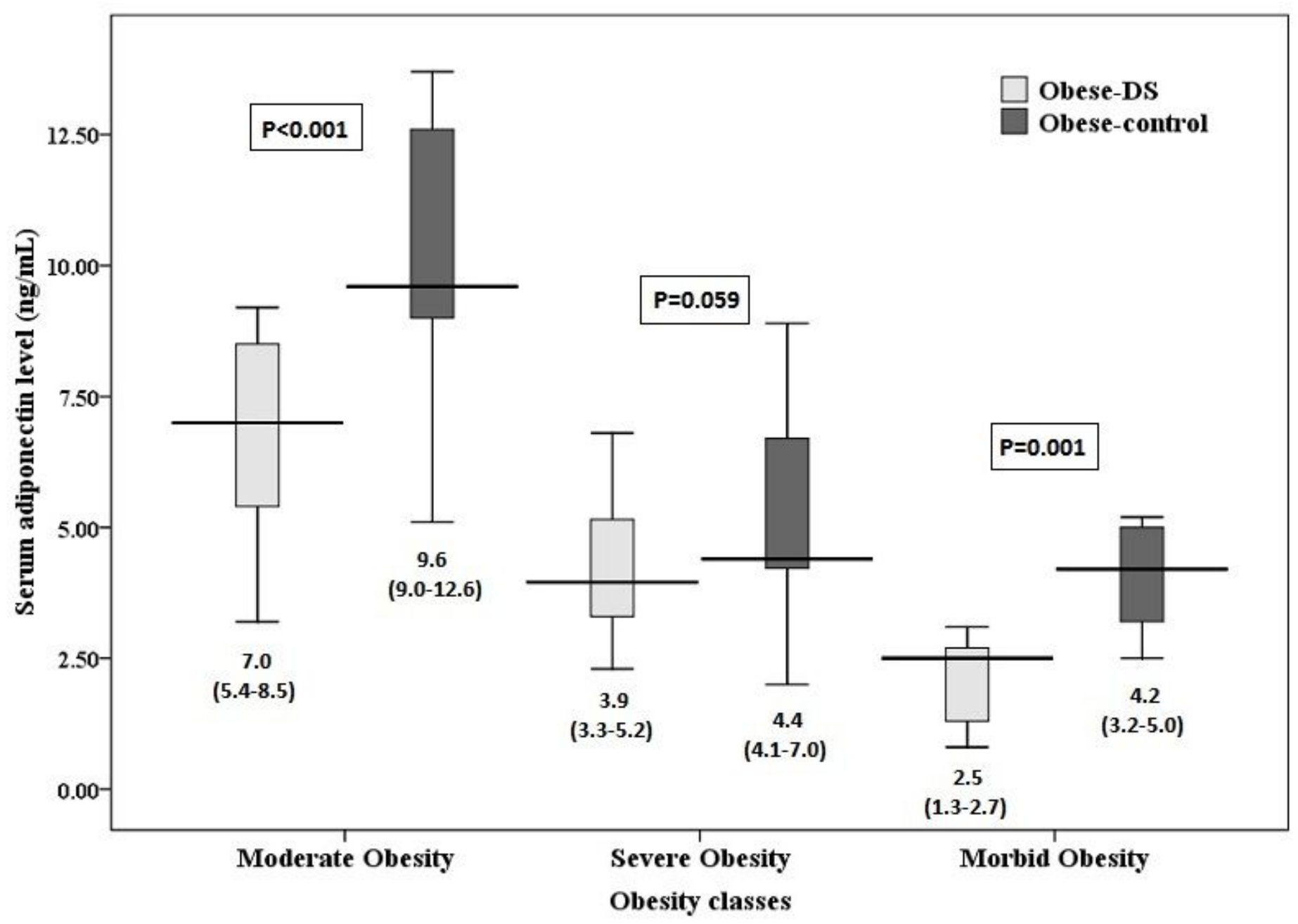

Figure 1

Serum adiponectin concentrations among obese-DS and obese-control groups according to the severity of obesity 


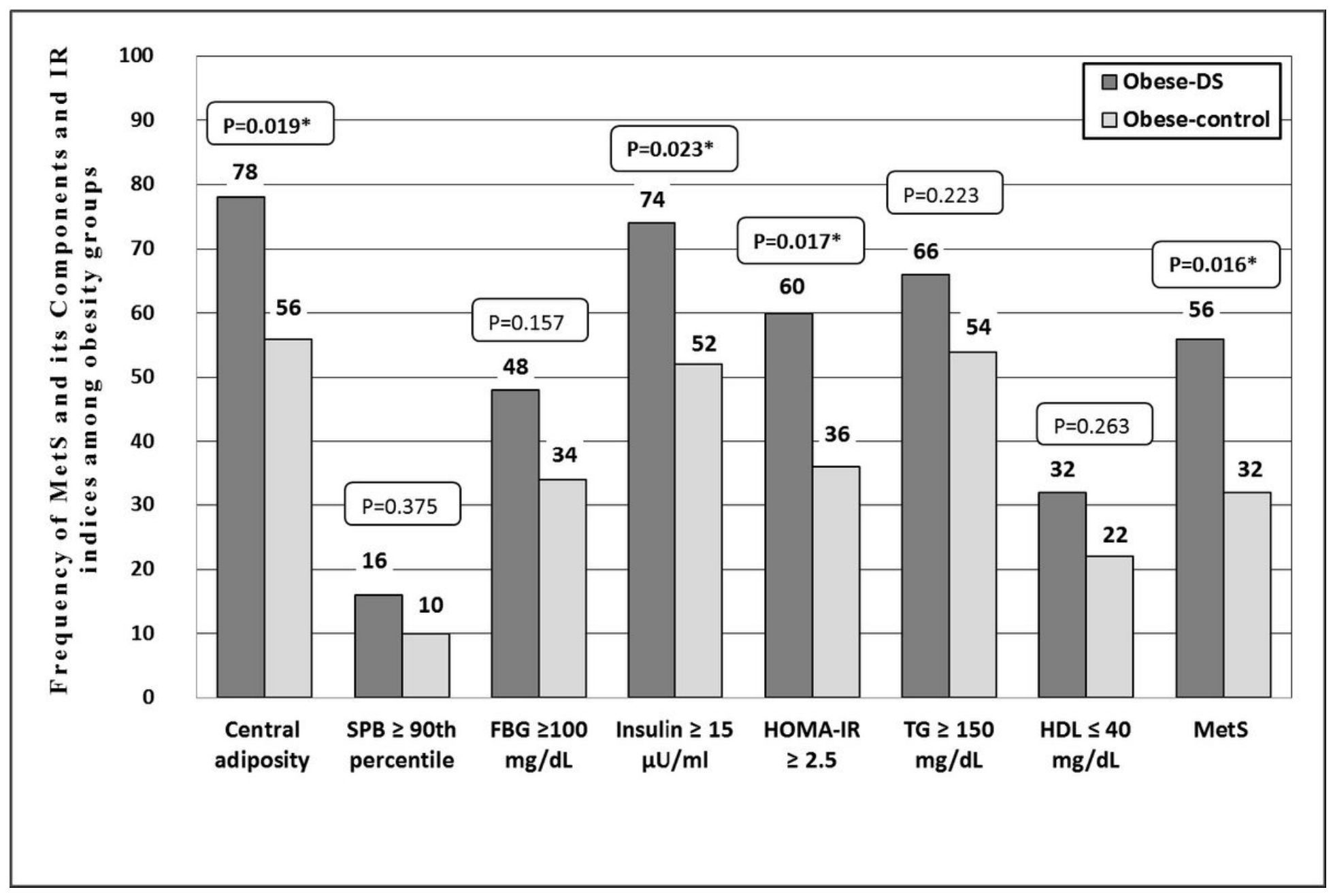

Figure 2

Frequency of metabolic syndrome, altered components of MetS and insulin resistance indices among obese-DS and obese-control groups 


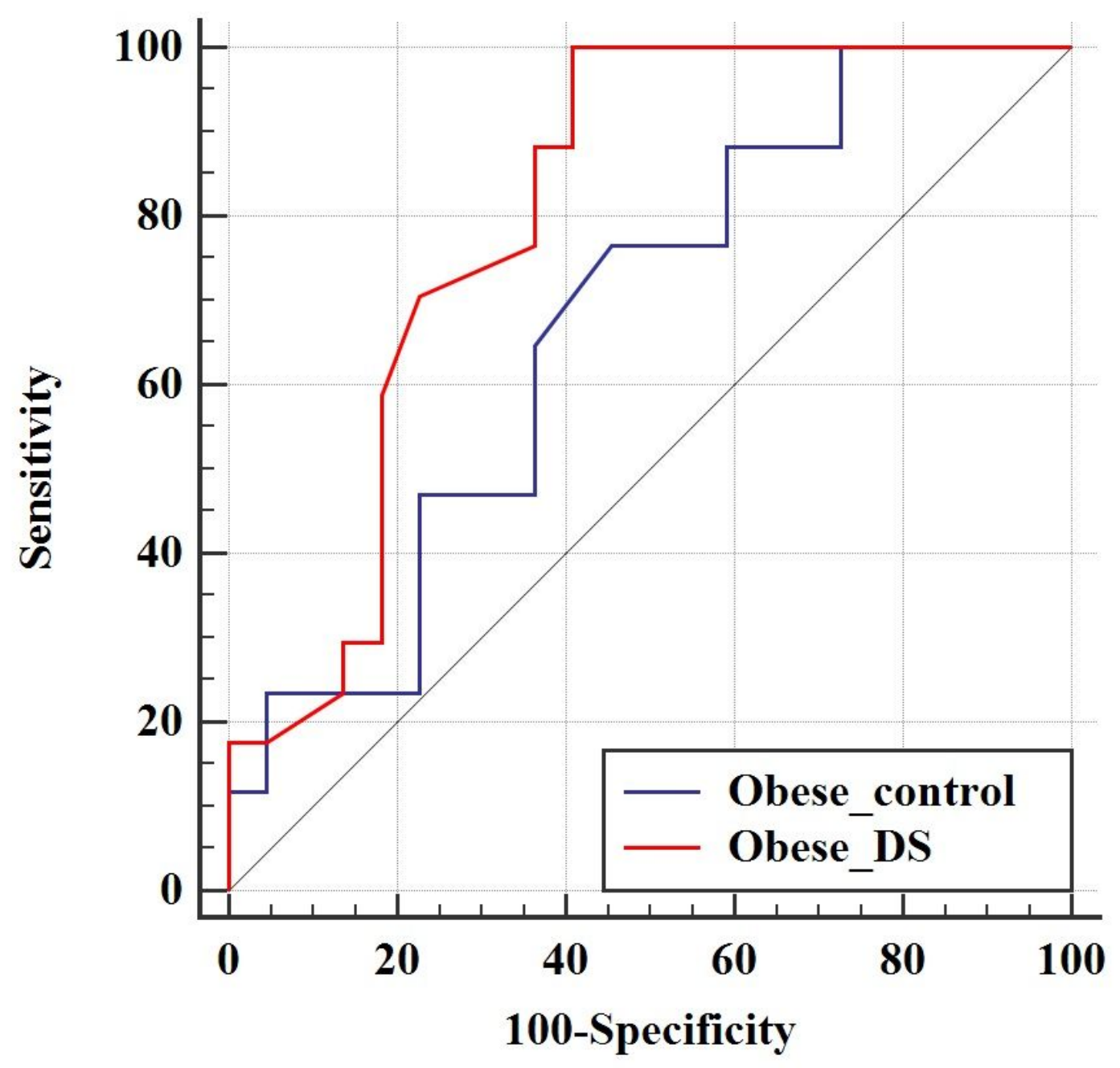

Figure 3

Receiver operating characteristic (ROC) curve for identification of metabolic syndrome according to serum adiponectin among obese-DS and obese-control groups 